\title{
¿El diálogo como arma? La lucha de los tribunales regionales contra la fragmentación del derecho internacional de los derechos humanos
}

Dialogue as a weapon? The battle of regional tribunals against the fragmentation of international human rights law

Bruno Rodríguez Reveggino ${ }^{\mathrm{I}}$

Corte Interamericana de Derechos Humanos

\section{Resumen}

La Corte Interamericana de Derechos Humanos (Corte IDH), el Tribunal Europeo de Derechos Humanos (TEDH) y la Corte Africana de Derechos Humanos y de los Pueblos (Corte Africana) sostienen un "diálogo judicial" de manera continua. Este artículo argumenta que el diálogo contribuye principalmente a dos aspectos sustanciales. Primero, es un elemento clave para evitar una fragmentación interna al Derecho Internacional de los Derechos Humanos (DIDH). Segundo, contribuye a la legitimación de cada uno de los sistemas regionales al momento de dotar de contenido y alcance a las obligaciones existentes en los tratados constitutivos. Se concluye que, en la medida en que se amplíe el diálogo y se consolide su utilización, se permitirá dotar de mayor coherencia a los sistemas regionales de protección de los derechos humanos.

\section{Palabras clave}

Diálogo judicial / Corte Interamericana de Derechos Humanos / Tribunal Europeo de Derechos Humanos / Corte Africana de Derechos Humanos y de los Pueblos / Fragmentación del derecho internacional / Legitimidad de tribunales internacionales.

\section{Summary}

The Inter-American Court of Human Rights, the European Court of Human Rights and the African Court of Human and Peoples' Rights maintain an ongoing "judicial dialogue". This article argues that the dialogue contributes mainly to two substantive aspects. First, it is a key element to avoid an internal fragmentation of International Human Rights Law. Second, it contributes to the legitimacy of each of the regional systems since it provides scope and content to the obligations established in each of the constituent treaties. It is concluded that, insofar as the dialogue is broadened and its use is consolidated, it will contribute to give more coherence to regional human rights protection systems.

\section{Keywords}

Judicial Dialogue / Inter-American Court of Human Rights / European Court of Human Rights / International Criminal Court of Human Rights and Peoples / Fragmentation of International Law / Legitimacy of International Tribunals.

\section{Introducción}

Cada vez con mayor intensidad puede evidenciarse el diálogo judicial entre la Corte Interamericana de Derechos Humanos (Corte IDH), el Tribunal Europeo de Derechos Humanos (TEDH)

\footnotetext{
${ }^{1}$ Abogado de la Secretaría de la Corte Interamericana de Derechos Humanos. Se recibió summa cum laude de la Maestría (LLM) en Derecho Internacional de los Derechos Humanos de la Universidad de Notre Dame, Estados Unidos y de la carrera de Derecho de la Universidad Católica San Pablo, Perú. Las opiniones vertidas en este artículo son de responsabilidad exclusiva del autor y no representan de ninguna manera la posición de la Corte Interamericana de Derechos Humanos ni de su Secretaría.
} 
y la Corte Africana de Derechos Humanos y de los Pueblos (Corte Africana). Este trabajo busca esbozar de manera breve los aspectos centrales de este diálogo judicial entre sistemas regionales, así como demostrar que las características de este parecen contribuir especialmente a dos aspectos sustanciales. Se sostiene que el diálogo, por un lado, sirve para contrarrestar la problemática de la fragmentación del derecho internacional de los derechos humanos, mientras que, por el otro, busca aumentar la legitimidad de los tribunales regionales.

Este trabajo está pensado a manera de iniciar una discusión, que permita al lector preguntarse si efectivamente estos puentes tendidos a través de los continentes, pueden permitir mayor coherencia dentro del derecho internacional de los derechos humanos y mejorar la comprensión regional de éste. No se busca abordar todos los aspectos críticos sobre cómo se ha entablado el diálogo o los efectos concretos en casos específicos. En su lugar, desde una perspectiva global, evidenciando el proyecto a largo plazo que han emprendido los tribunales regionales.

En primer lugar, se establecerán las características del diálogo judicial. En segundo lugar, se planteará el problema de la fragmentación y cómo el diálogo puede contribuir a reducir esta problemática. En tercer lugar, se describirá la utilización del diálogo judicial al momento de dotar de alcance y contenido a los derechos contenidos en los instrumentos internacionales que se encuentran bajo jurisdicción de los tribunales regionales, y cómo ésta puede generar mayor legitimidad.

\section{Características del diálogo}

Aunque es pocas veces definido, el diálogo jurisprudencial ha sido considerado por el Juez de la Corte Interamericana, Eduardo Ferrer Mac-Gregor, como:

La práctica de las cortes nacionales e internacionales, a través de la cual se utiliza la argumentación de otras cortes con el fin de construir a una mejor interpretación de las normas de derechos humanos y, en general, de cualquier otra norma contenida en una constitución o en un tratado (Ferrer, 2013).

Todo parece señalar que no es un concepto únicamente jurídico (García Roca, 2013, p. 223), sino que parece insertarse en un "proyecto jurídico, político y cultural" más amplio (Von Bogdandy, 2014, p. 4). Autores como Von Bogdandy o Morales Antonazzi se aproximan al concepto del diálogo desde la formación de un ius commune, es decir, una mirada "transformadora del derecho público", donde no sólo el Estado es el "principal poder público, sino que las instituciones internacionales y supranacionales influyen de manera significativa en la convivencia social y en el ejercicio del poder público de los Estados" (Von Bogdandy, 2014, p. 4). En este orden de ideas la motivación principal del diálogo parece no sólo resolver los casos concretos de una manera más justa, sino también termina siendo la consolidación de un derecho común más sólido y coherente.

Partiendo de la crítica de Vergottini sobre el uso del concepto de diálogo, García Roca explica que contrariamente a un diálogo entre cortes domésticas, el diálogo entre las Cortes supranacionales tiene características especiales, ya que estos sistemas son independientes el uno del otro (García Roca, 2013, p. 223). También, Guillem Cano expresa que este tipo de interacción se ha llevado a cabo de una manera informal, y no obligatoria ya que no existe un elemento vinculante que exija estos tribunales a interactuar con miras a una retroalimentación mutua (Cano, 2015, p. 48).

Cano se refiere por ejemplo al uso por parte de los tribunales de jurisprudencia desarrollada por las otras cortes regionales para inspirarse en el momento de interpretar los 
derechos reconocidos en sus respectivos textos fundamentales (p. 48). Cano también explica que el desarrollo de los derechos fundamentales es similar a un case law. Esto implica que los textos que contienen los derechos humanos sean interpretados en relación con el contexto, cultura, valores y realidades sociales. De esta forma, también se reconoce que el derecho internacional de los derechos humanos está en una constante evolución y debe siempre ser interpretado teniendo en cuenta el contexto (Corte IDH, 2012, Caso Artavia Murillo "Fecundación in vitro" Vs. Costa Rica).

Es entonces preciso identificar a continuación, sin querer establecer una definición exacta del concepto de diálogo, algunas características particulares del diálogo judicial entre las cortes regionales de derechos humanos.

\subsection{Origen, reglas y principios de interpretación similares}

Una de las primeras notas particulares que vemos es que el diálogo se da en sistemas que tienen un origen común, así como reglas y principios de interpretación similares. Originalmente un régimen universal bajo el sistema de la Organización de las Naciones Unidas (ONU) sirvió como base para el establecimiento de un reconocimiento de los derechos humanos bajo principios de indivisibilidad, universalidad y solidaridad (Zehra, 2006, p. 419). En consecuencia, la fuente de origen de los derechos que cada tribunal examina es la dignidad y el valor del ser humano. Posterior al establecimiento de la Carta de la ONU, los textos constitutivos de las tres cortes, así como las convenciones de derechos humanos que cada sistema aplica se derivan de la Declaración Universal de los Derechos Humanos.

Los derechos protegidos y aplicados por los Tribunales son similares dado que las fuentes de derecho son comunes a los tres sistemas, y los principios y reglas de interpretación provienen del derecho internacional público y las particularidades del derecho internacional de los derechos humanos. De esta manera, en el prefacio del primer libro publicado en 2015 por dos cortes regionales, la Corte IDH y el Tribunal Europeo, "Diálogo Transatlántico: Selección de Jurisprudencia del Tribunal Europeo y la Corte Interamericana de Derechos Humanos" (Corte IDH y TEDH, 2015, p.3), los secretarios de los dos tribunales mencionan:

La importancia de esta cooperación debe ser reconocida, dada la similitud de los derechos y libertades protegidos por los respectivos tratados fundacionales de ambas cortes, así como la existencia en ambos sistemas de criterios de admisibilidad y principios de interpretación muy parecidos. Además, la creciente convergencia en las temáticas planteadas ante ambas jurisdicciones confiere una nueva y mayor relevancia a sus respectivas jurisprudencias (2015, p. 3).

La Corte IDH ha determinado que los Artículos 31 y 32 de la Convención de Viena sobre el Derecho de los Tratados (Convención de Viena) recogen la regla general y consuetudinaria de interpretación de los tratados internacionales. Así, la Corte analiza en sus opiniones consultivas y en las sentencias de los casos contenciosos los siguientes aspectos de acuerdo a la Convención de Viena: a) sentido corriente del término y buena fe, b) objeto y fin del tratado, c) contexto interno del tratado, d) interpretación evolutiva y, e) otros métodos complementarios como los trabajos preparatorios de la Convención Americana (Corte IDH, 2016a, Opinión Consultiva OC-22, párr. 36).

La Corte IDH ha establecido "según el criterio sistemático, [que] las normas deben ser interpretadas como parte de un todo cuyo significado y alcance deben fijarse en función del sistema jurídico al cual pertenecen” (Corte IDH, 2009, Caso González y otras "Campo Algodonero" Vs. México, parr. 191). 
Adicionalmente, de acuerdo al Artículo 29 de la Convención Americana, un estudio de la interpretación evolutiva por la Corte IDH reconoce como instrumentos vivos a los tratados de derechos humanos, por lo cual la Corte debe también tener en cuenta los cambios sociales y las condiciones de vida contemporáneas cuando está interpretando la Convención Americana (Corte IDH, 2012, Caso Atala Riffo y Niñas Vs. Chile, párr.83).

Por su parte el TEDH también se refiere a los Artículos 31 y 33 de la Convención de Viena en la interpretación de su Convención (Carrillo, 2009, p. 663-664). El TEDH reconoce en su proceso interpretativo, la naturaleza especial de los tratados de derechos humanos, al igual que la Corte IDH según el Artículo 29 de la Convención Americana.

Por ejemplo en el Caso Soering Vs. United Kingdom of Great Britain and Northern Ireland, el TEDH estableció que cualquier interpretación de los derechos garantizados bajo la Convención Europea "debe ser consistente con el espíritu general de la Convención, un instrumento designado para mantener y promover los ideales y valores de una sociedad democrática" (TEDH, 1989, Caso Soering Vs. Reino Unido, párr. 87). El TEDH también ha reconocido que los tratados de derechos humanos son instrumentos vivos cuya interpretación deben estar acorde al cambio de los tiempos y la vida actual (TEDH, 1978, Caso Tyrer Vs. Reino Unido, párr. 31).

La Corte Africana también tiene en cuenta al sistema universal y se refiere a la jurisprudencia del TEDH y de la Corte IDH. El propio Protocolo a la Carta Africana de Derechos Humanos y de los Pueblos en sus Artículos 3 y 7 contiene provisiones más amplias en cuanto a la jurisdicción de la Corte, así como de las fuentes del derecho.

Es necesario ilustrar esto con un ejemplo. En su decisión de 2011 en Rev Christopher Mitikila v. Tanzania, la Corte Africana analizó los límites que al Artículo 27 (2), podrían tener sobre el derecho a la libre participación en el gobierno de su país, protegido bajo el Artículo 13 (1) de la Carta Africana. En la interpretación la Corte consideró dos instrumentos base del régimen universal de los derechos humanos: la Declaración Universal de Derechos Humanos, Artículo 21 (1), y el Pacto Internacional de Derechos Civiles y Políticos (ICCPR, por su sigla en inglés), Artículos 3 y 25.

La Corte Africana reafirmó el uso del test de proporcionalidad usado por la Comisión Africana bajo Artículo 27 (2) de la Carta Africana. El test permite evaluar si la restricción se da por una ley domestica de "aplicación general", de manera que se hace un balance del impacto, naturaleza y alcance de la limitación frente al interés legítimo del Estado (Corte Africana, 2013, Rev Christopher Mitikila v. Tanzania, párr. 106.1). En su análisis la Corte Africana concluyó que este test es similar al test de proporcionalidad utilizado por el TEDH en el caso Handyside Vs. Reino Unido de 1976. También comparó el test usado por la Corte IDH en el caso Baena Ricardo Vs. Panamá de 2001 bajo los Artículos 30 y 32.2 de la Convención Americana, los cuales requieren que los límites sean dados por un acto legislativo y que las restricciones sean legales y legítimas.

La Corte Africana concluyó entonces que los límites a los derechos y libertades bajo la Carta Africana son solamente aquellos bajo el Artículo 27(2) de la Carta y que dichos límites deben "tomar la forma de una ley de aplicación general y deben ser proporcionales y legítimos al objetivo" (Corte Africana, 2013, Rev Christopher Mitikila v. Tanzania, 2011, párr. 107.1).

\subsection{Se realiza sin originarse de una obligación legal}

No existe una obligación legal, ni disposición vinculante que determine la existencia del diálogo entre las cortes, pero tampoco hay una regla que restrinja esta interacción. A diferencia de otros 
sistemas en los cuales los mecanismos de resolución de disputas se limitan a ciertos acuerdos internacionales aplicables únicamente al régimen, como por ejemplo la aplicación exclusiva de los textos de la Organización Mundial del Comercio (OMC) por su Mecanismo de Resolución de Disputas, las tres cortes regionales poseen argumentos legales objetivos que les permiten considerar en sus decisiones la jurisprudencia de otras cortes como elementos persuasivos.

La lógica no vinculante también se debe a que los tres tribunales poseen una exclusividad geográfica que les permite relacionarse entre sí de manera horizontal y con igualdad de estatus, siendo cada uno autoridad para los Estados bajo su jurisdicción. Por lo cual, el diálogo permite conocer los estándares desarrollados por cada tribunal y aplicables a sus realidades particulares, con la posibilidad de diferenciarlos de estándares usados en otra región; usarlos como inspiración, e incluso adaptarlos.

De igual manera se reconoce que el punto base de un diálogo profundo, es conocer bien a los interlocutores, así como el contexto dentro del cual matizan sus opiniones. Es necesario recordar que el diálogo se realiza de una manera horizontal y de manera no vinculatoria (García Roca, 2013, p. 76). Por ello identificamos que el diálogo entre instituciones sirve para sentar las bases de un diálogo reflejado a nivel jurisprudencial.

\subsection{Es diálogo entre iguales}

Los tribunales regionales, y en representación sus funcionarios y jueces, como autores del diálogo, se relacionan desde una posición de igualdad en la cual ninguno posee autoridad superior a los otros, y en el que cada uno tiene una jurisdicción regional exclusiva. Este ingrediente es indispensable para un desarrollo del DIDH capaz de adaptarse a las particularidades contextuales de cada región.

Como bien se sabe, cada tribunal fue concebido en el seno de una organización regional: la Corte IDH hace parte de la Organización de los Estados Americanos establecida en 1948; el TEDH del Consejo de Europa fundado en 1949; y, la Corte Africana de la Unión Africana que remplazó en el 2002 a la Organización para la Unión Africana (Heyns, 2009, p. 928). Como parte de organizaciones regionales, sus estados miembros son distintos y sólo pueden pertenecer a una organización regional dependiendo de su localización geográfica. Los tres tienen función contenciosa y consultiva, y permiten peticiones individuales. Sin embargo, la Corte IDH y la Corte Africana poseen un filtro realizado por una comisión frente a la cual individuos podrían acudir. Por lo cual, solamente el Tribunal Europeo permite que individuos, grupos de individuos o ONGs se dirijan directamente a éste.

\subsection{Es un proyecto político}

El ex Presidente del Tribunal Europeo, Dean Spilmann señaló que el "diálogo o interacción judicial entre la Corte de San José y el Tribunal de Estrasburgo no hubiera sido posible sin la existencia de una relación institucional fluida entre ambas jurisdicciones" (Steiner, 2014, p, 15). Asimismo, el Presidente de la Corte Interamericana, Juez Roberto F. Caldas destacó en su discurso inaugural del año judicial 2016 "que la presencia del [entonces] Presidente de la Corte Africana, Agustino Ramadani [y] del [entonces] Presidente de la Sección Tercera del Tribunal Europeo de Derechos Humanos, Luis López Guerra simbolizan las fuertes relaciones de diálogo y cooperación entre nuestras instituciones" (Caldas, 2016). Para el Presidente Caldas esto se enmarca en el "compromiso que tiene este Tribunal con el diálogo con la sociedad y las instituciones" (2016). La marcada voluntad política se ha visto materializada en diversas visitas y un programa de intercambio del personal de Secretaría entre la Corte IDH y el TEDH.

Las visitas de los jueces de la Corte IDH al TEDH y a la Corte Africana, así como 
las visitas de jueces de estos tribunales a nuestra sede en San José, han permitido que los jueces intercambien experiencias y puntos de vista sobre las similitudes entre los tribunales regionales, así como los retos comunes o particulares en cada una de las respectivas jurisdicciones. Por ejemplo, en 2012 y 2016 la Corte IDH recibió visitas de delegaciones de jueces del TEDH en la sede en San José de Costa Rica. De igual manera, jueces de nuestra Corte han visitado el TEDH en 2011, 2012, 2014 y 2015.

En cuanto a la Corte Africana de Derechos Humanos y de los Pueblos, en su sede, recibió la visita de la Corte Interamericana, por el entonces Presidente, Juez Augustino Ramadhani en el 2012 y 2016. Asimismo, en noviembre de ese mismo año, los jueces de la Corte IDH y el Secretario, visitaron la Sede de la Corte Africana en Arusha. En 2016 se firmó un convenio de cooperación entre ambas instituciones. En octubre de 2015, miembros de la Secretaría de la Comisión Africana también visitaron San José en el marco de un programa de capacitación dictado por funcionarios de la Secretaría de la Corte Interamericana sobre aspectos centrales de la jurisprudencia, así como cuestiones administrativas y de procedimiento.

Adicionalmente, bajo un convenio firmado en 2013 entre la Corte IDH y el Tribunal Europeo, se estableció un programa de intercambio de abogados, mediante el cual un abogado de cada respectivo tribunal visitó al otro durante algunos meses para así profundizar y familiarizarse con los procedimientos, jurisprudencia, y dinámicas de la otra región. El abogado visitante se incorporaba a un equipo de trabajo, y además de realizar funciones cotidianas del tribunal, se buscaba identificar buenas prácticas aplicables al trabajo de ambos órganos (Corte IDH, 2016b, Informe Anual 2016, p. 194).

\subsection{Los objetos del diálogo están en constante evolución}

La naturaleza cambiante de los derechos humanos invita a una interacción constante entre órganos de toma de decisiones en materia internacional. Como habíamos señalado, la Corte IDH y el TEDH han reconocido a los tratados de derechos humanos como instrumentos vivos. Más adelante, se detallará algunos ejemplos del diálogo entre tribunales que ha permitido actualizar el derecho interamericano y europeo y cómo este instrumento permite la legitimación de los nuevos contenidos y alcance del que se dota a estos derechos.

\subsection{Se enmarca en un contexto de diálogo entre tribunales nacionales}

El diálogo entre cortes regionales se enmarca en un fenómeno aún mayor de "comunicación transjudicial", que se da en diversos niveles, tanto locales, nacionales e internacionales (Slaughter, 1994). En el ámbito interamericano se ha desarrollado especialmente la doctrina del control de convencionalidad que permite catalizar este diálogo (González, 2014, p. 34), mientras que en el sistema europeo se evidencia a partir de la noción de consenso regional (Neuman, 2008, pp. 101-123). Las implicancias de este diálogo judicial en el ámbito interamericano han llevado a algunos autores a enmarcarlo dentro de un ambicioso proyecto de formación de un derecho común latinoamericano o "ius commune lationamericano" (Von Bogdandy, 2014).

\section{El problema potencial de la fragmentación del DIDH}

Uno de los principales desafíos por los que atraviesa el Derecho Internacional es su fragmentación. La Comisión de Derecho Internacional ha identificado tres formas de conflictos legales producidos por la fragmentación del derecho internacional público: aplicaciones particulares de principios interpretativos que difieren del derecho internacional general, la aplicación de una ley particular en vez de una general, y un enfrentamiento entre 
dos obligaciones internacionales aplicables pero provenientes de regímenes especializados distintos (Comisión en Derecho Internacional, 2006, párr. 447).

Una cuarta forma de fragmentación que nos preocupa tiene relación con el desarrollo del derecho internacional de los derechos humanos. Esta es una fragmentación interna producida por la multiplicidad de tratados y órganos de decisión con capacidad de interpretación e implementación. En este contexto, el contenido de un derecho que ha sido reconocido en varios tratados puede ser definido de maneras distintas (Garlicki, 2012, p. 27). Por ello, a pesar de un aparente reconocimiento general de jure de un derecho, es posible que de facto no se entiendan las mismas protecciones a los individuos y deberes de los Estados para la realización efectiva de dicho derecho.

El derecho internacional es un sistema legal de naturaleza descentralizada (Dauvergne, 2007, p. 540). A diferencia del orden doméstico, a nivel internacional, no existe una constitución global, un legislador o una corte suprema capaz de resolver conflictos entre las distintas ramas del derecho internacional público, o reconciliar la creciente multiplicidad de regímenes internacionales que se desarrollan de manera aislada los unos de los otros. Pauwelyn explica que en este contexto los Estados actúan frecuentemente como legisladores en distintos escenarios. Esta capacidad de los Estados se fundamenta en el carácter soberano de cada Estado, junto con los principios de igualdad, el principio de auto preservación, y de no intervención en los asuntos internos de cada Estado. Entonces, la aplicación de las leyes creadas a nivel internacional por acuerdo entre soberanos, corre el riesgo de que a pesar de que el tratado haya sido incorporado y reconocido en el orden legal doméstico, distintos tribunales internacionales pueden interpretar el contenido de los derechos de una forma desigual.

No sólo existe una extensa variedad de tratados internacionales, sino también de regímenes con sus propios tribunales, cada cual cuenta con capacidad de decisión y autoridad de interpretación. Así, por ejemplo, el mecanismo de resolución de disputas de la Organización Mundial del Comercio, el Tribunal Internacional del Derecho del Mar, y los Tribunales Regionales de derechos humanos; caso que nos concierne en el presente artículo.

En este contexto, la fragmentación se entiende como una "situación en que distintas medidas de políticas públicas se sobreponen en el contexto legal internacional" (Trachtman, 2013, p. 45). Una vez que dichas medidas se aplican simultáneamente hay posibilidades de conflictos entre las leyes aplicables, las cuales, aunque contradictorias o contrarias entre sí, son individualmente válidas y legítimas. Por lo cual, la manifestación más problemática de la fragmentación es la imposibilidad de implementar o de hacer cumplir simultáneamente leyes incompatibles.

Normas potencialmente conflictivas son aquéllas con carácter vinculante que han sido aceptadas por los Estados, específicamente en casos en los cuales un adjudicador internacional se encuentra frente a dos normas aplicables a la misma situación, pero contradictorias, y una interpretación armónica no sea posible (Pauwelyn, 2003, p. 6). En el caso de los derechos humanos no es necesario que se llegue a un conflicto para entender las dificultades de la fragmentación.

Se ha reconocido que a pesar de que los sistemas regionales de protección de los derechos humanos se basan en el sistema universal, los textos que cada sistema interpreta contienen diferencias "esporádicamente sustanciales" las cuales también provocan cambios en el contenido de los derechos al momento de interpretar (García Roca, 2012, pp. 79-83).

Por ello, la misma particularidad del régimen de los derechos humanos nos enfrenta al desafío de conciliar dos intereses esenciales en un contexto fragmentado: primero, lograr la implementación de los derechos por distintas jurisdicciones, teniendo en cuenta las 
particularidades contextuales y regionales; y segundo, mantener una coherencia entre las interpretaciones hechas por cada tribunal regional. Lech Garlicki, antiguo juez del TEDH, escribió recientemente sobre el riesgo de que el TEDH se vuelva autónomo y autárquico en relación con el derecho internacional de los derechos humanos. En consecuencia "aquellos estándares judicialmente elaborados comienzan a diferenciarse de los estándares internacionales adoptados a nivel mundial”, en este orden de ideas especificó:

Standards emerging from the judicial interpretation of the European Convention are not necessarily the same as standards resulting from the interpretation of other, universal and regional, human rights instruments.

In consequence, the human rights adjudication in Europe is developing mostly through a concurring application of the European Convention and national constitutional instruments (Garlicki, 2012, p. 34).

No obstante, el fenómeno de la fragmentación no es en sí mismo un problema. De hecho, algunos autores mencionan que la concepción de la fragmentación como una dificultad para el derecho internacional, se basa en la idea errónea de que el derecho internacional debe constituir un conjunto homogéneo. Koskenniemi explica que la idea de una unidad de las leyes internas es ajena a los ordenamientos domésticos en los cuales existe una jerarquía entre cortes de distintos niveles, en los que cortes supremas se encargan de reconciliar principios, y contradicciones entre leyes aplicables simultáneamente (Koskemieni, 2005).

Por ello, sin tener que recurrir a una unificación sistemática del DIDH, el diálogo entre los tribunales regionales se presenta como una herramienta que reconoce la jurisdicción exclusiva de cada tribunal regional en su respectivo continente; da la flexibilidad a cada tribunal del nivel de consideración de los estándares, interpretaciones y procedimientos de otras cortes; pero, al mismo tiempo, permite una actualización y conversación constante entre los tres sistemas. Además, esta discusión se complementa con el principio de subsidiaridad que nutre a los sistemas regionales, en el sentido de que no necesariamente todas las respuestas a las problemáticas similares en cada región deben ser iguales, sino que se debe permitir cierto margen de apreciación atendiendo a las propias características: sociales, históricas, jurídicas, e incluso económicas de cada región. Por lo que, en tanto el diálogo no es vinculante, permite ahondar en lo más necesario, es decir, en la comunicación, y alejarse en cuanto implique una respuesta propia de un sistema regional determinado.

\section{El diálogo como factor de legitimación}

Como vimos, los tribunales regionales están facultados para conocer cualquier caso relativo a la interpretación y aplicación de sus instrumentos constitutivos. Éstos, al momento de resolver casos concretos, a su vez, desarrollan el alcance y contenido de los derechos humanos consagrados en dichos instrumentos. Esta labor, permite actualizar los contenidos propios de la Convención Americana, reconociendo incluso derechos implícitos (Gross Espiell, 2000, p.46) cuando sea necesario. Tal como habíamos señalado, se considera que los tratados de derechos humanos son "instrumentos vivos". A continuación, me referiré a dos ejemplos en los cuales se ilustra la evolución de dos derechos protegidos bajo la Convención Americana y los otros sistemas regionales.

\subsection{Determinación del inicio de la vida}

En el caso Artavia Murillo y Otros (“fecundación in vitro") vs. Costa Rica la Corte IDH examinó el contenido de la definición de la protección del derecho a la vida bajo el Artículo 4.1 de la 
Convención Americana, en el contexto de derechos sexuales y reproductivos. Este fue el primer caso ante la Corte IDH sobre el tema, desarrollado bajo hechos que ocurrieron en Costa Rica a partir del 15 de marzo de 2000 cuando la Corte Suprema declaró como inconstitucional y anuló el Decreto Ejecutivo del Ministerio de Salud que permitía y regulaba una técnica de fecundación in vitro (FIV). Como argumento principal en la decisión de la Corte Suprema, la protección absoluta del derecho a la vida no permitía la FIV debido a la pérdida de embriones que esta podía ocasionar. El Artículo 4.1 señala que "toda persona tiene derecho a que se respete su vida. Este derecho estará protegido por la ley y, en general, a partir del momento de la concepción. Nadie puede ser privado de la vida arbitrariamente" (Convención Americana, 1969).

La Corte IDH analizó en detalle el argumento principal desarrollado por Costa Rica: "la Convención Americana obliga a efectuar una protección absoluta del 'derecho a la vida' del embrión y, en consecuencia, obliga a prohibir la FIV por implicar la pérdida de embriones" (Corte IDH, 2012, Caso Artavia Murillo "Fecundación in vitro" Vs. Costa Rica, párr. 162). En su análisis el Estado de Costa Rica argumentó que la prohibición no era absoluta, pero que se limitaba a la técnica específica bajo el Decreto Ejecutivo. En este sentido el Estado interpretó el Artículo 4.1 de la Convención entendiendo que debido a que "en un porcentaje considerable de los casos" los embriones considerados como vida humana no eran viables (2012, párr. 155).

En su análisis la Corte examinó con detenimiento la interpretación que el Estado hizo del Artículo 4.1 respecto a la palabra "concepción", dando especial consideración al criterio que guarda la Corte IDH en América Latina como intérprete último de la Convención. Por ello la Corte IDH examinó si la interpretación del Estado era admisible a la luz de la Convención y considerando las fuentes de derecho internacional pertinentes.

En esta ocasión el Estado también argumentó que otros tratados exigen la protección absoluta de la vida prenatal, entre ellos la Declaración Universal de Derechos Humanos y el Pacto Internacional de Derechos Civiles y Políticos. Entonces, la Corte IDH analizó lo dispuesto por el Sistema Universal, el europeo y el africano (2012, párr. 192). Para ello, la Corte citó el Convenio Europeo de Derechos Humanos, la Carta Africana sobre los Derechos Humanos y de los Pueblos, y la jurisprudencia de ambos sistemas; solamente el TEDH contaba con precedentes. La Corte IDH citó el Caso Vo. Vs. Francia, en el que el TEDH dictó que el embrión o feto requiere protección en nombre de la dignidad humana "sin hacerlo en nombre del 'derecho a la vida" (TEDH, Caso Vo. Vs. Francia, 2004, párrs. 75, 82, 84 y 85). Dicho pronunciamiento es reiterado en el Caso Evans Vs. Reino Unido: "un embrión no tiene intereses y no puede alegar —o alegar en su nombre- un derecho a la vida" (TEDH, 2007, Caso Evans Vs. Reino Unido, párr. 54).

Luego de haber analizado los sistemas regionales y el sistema universal, y de haber utilizado otros métodos de interpretación, la Corte IDH concluyó que “concepción” bajo el Artículo 4.1 de la Convención Americana empieza cuando el embrión se implanta al útero, por lo que la interpretación del Estado de Costa Rica no fue adecuada.

\subsection{Las características de la esclavitud contemporánea}

El significado de la esclavitud contemporánea es un ejemplo ideal de la evolución constante de los derechos humanos a través de cambios históricos y sociales, según fue establecido por la Corte IDH en el Caso Hacienda Brasil Verde Vs. Brasil, de 2016. Para su análisis la Corte IDH realizó un amplio diálogo con otros tribunales y órganos internacionales de protección de los derechos humanos. Si bien la prohibición de la esclavitud ha sido reconocida como ius cogens, la Corte ha seguido el reconocimiento internacional de la prohibición de la esclavitud como 
norma imperativa del derecho internacional la cual conlleva a obligaciones erga omnes y cuyo contenido debe desarrollarse a la par de los cambios sociales y contextuales.

La Corte IDH estableció nuevos estándares en cuanto al contenido de la prohibición de la esclavitud, servidumbre, trabajo forzoso y trata de personas, dado que este fue el primer caso contencioso que este Tribunal conoció al respecto. En particular, la Corte consideró:

Útil y apropiado utilizar otros tratados internacionales distintos a la Convención, para interpretar sus disposiciones de acuerdo a la evolución del sistema interamericano, habida consideración del desarrollo experimentado en esta materia en las varias ramas del derecho internacional, en particular el derecho internacional de los derechos humanos (2016, párr. 112).

En su análisis, la Corte consideró la Declaración Universal de Derechos Humanos, el Pacto Internacional de Derechos Civiles y Políticos de 1966, el Convenio Europeo de Derechos Humanos y la Carta Africana de Derechos Humanos y de los Pueblos, entre otros. También citó la jurisprudencia del TEDH, en el Caso Rantsev Vs. Chipre y Rusia donde el TEDH se apartó de una definición clásica de esclavitud, para así reconocer la evolución que este concepto ha tenido, tal como lo había interpretado inicialmente el Tribunal Penal Internacional Ad Hoc para la ex Yugoslavia en el Caso Kunarac. La Corte IDH se refirió a la Comisión Africana de Derechos Humanos y de los Pueblos, en su Caso Malawi African Asociación y otros Vs. Mauritania para ver cómo se identificaban en el sistema africano las prácticas análogas o contemporáneas a la esclavitud.

Adoptando un criterio distinto al sentido tradicional de la esclavitud, que suponía la propiedad en sentido formal sobre una persona, la Corte IDH concluyó que de acuerdo al desarrollo del concepto de la esclavitud debe mirarse los hechos concretos, teniendo en cuenta como base, la manifestación de "atributos del derecho de propiedad"; de una manera similar a lo decidido por el Tribunal Penal Internacional $A d H o c$ para la exYugoslavia. Entre estos elementos se encuentra la restricción o control de la autonomía individual y el uso de violencia física o psicológica. En esta misma línea, la Corte IDH identificó a la servidumbre como análoga a la esclavitud, así como la trata de esclavos y de mujeres, y el trabajo forzoso cuando cumple con los elementos descritos en el Caso de las Masacres de Ituango Vs. Colombia.

Ambos ejemplos nos permiten dar cuenta de una voluntad marcada por parte de la Corte Interamericana de dotar a sus decisiones de un amplio razonamiento, donde se incluyen sentencias de otros tribunales, tanto nacionales como internacionales. Esto, con el fin de actualizar los derechos y poder resolver el caso en concreto, de manera justa.

\section{Conclusiones}

Sostiene Von Bogdandy que el diálogo "conlleva ante todo la necesidad de justificar sus resoluciones fundamentándolas en argumentos suficientes" (Von Bogdandy, 2014, p. 21). Para él, tradicionalmente las decisiones tomadas por los tribunales se fundamentaban en su propia autoridad, sin embargo, "en el nuevo derecho público, los tribunales deben argumentar para convencer a otros actores jurídicos y justificar la toma de determinada decisión” (2014, p. 21). Coincide con el profesor alemán la recientemente electa Comisionada interamericana, Flavia Piovesan, al señalar además que el "profundo diálogo del Sistema Interamericano con la sociedad civil, [...] confiere legitimidad social gradual y creciente empoderamiento" (Piovesan, 2014, p. 75).

Tal como señalan Carozza y González "la protección universal de la dignidad humana y los derechos humanos es un proyecto plural” (Carozza, 2017, p. 436), donde los tratados, 
principios y reglas tienen que ser traídos a la vida en diferentes formas. El diálogo constituye un camino iniciado, pero no terminado para tender puentes entre los sistemas y contribuir a la formación de espacios comunes con aras a ampliar el espectro de protección de los derechos humanos. Como habíamos mencionado, algunos autores como Von Bogdandy, Morales Antonazzi y Piovesan sitúan al diálogo en el centro de un proyecto más grande, que es la consolidación de un sistema de "derecho común" (Von Bogdandy, 2014). Ciertamente, la idea del diálogo no sólo está inserta en las decisiones tomadas por los tribunales, sino también es un proyecto político. En este sentido, esta narrativa a favor del diálogo, consta en los discursos de los Presidentes de los tribunales, intercambios de personal entre las Secretarías o su participación en eventos académicos.

En el ámbito del diálogo con tribunales nacionales, es un hecho que dentro de los propios Estados puedan existir ciertas resistencias políticas o incluso jurídicas en la implementación de las decisiones de tribunales regionales. Un ejemplo de ello es el caso Hirst Vs. Reino Unido sobre el voto de los condenados a prisión, que aún no ha encontrado cumplimiento y ciertamente las declaraciones públicas dan cuenta de que no parece existir una voluntad de cumplir con lo ordenado por el TEDH. En el caso americano, lo ocurrido este año en la sentencia Fontevecchia d'Amico Vs. Argentina, donde la Corte Suprema de la Nación Argentina consideró que no correspondía dejar sin efecto una sentencia suya, como parte de la reparación de la Corte IDH, permite también dar cuenta de estas posibles tensiones. Sin embargo, es el propio diálogo el que parece imponerse a la hora de buscar soluciones que permitan hacer efectivas estas decisiones. Por lo que todo parece indicar que el diálogo llegó para quedarse.

Volviendo al diálogo entre tribunales regionales, en ninguno de los tres sistemas parece existir una metodología clara para su utilización, por lo que resulta difícil vislumbrar reglas determinadas para su implementación. El que sea un diálogo entre iguales, no vinculante y cuyo objeto está en constante evolución, parece dotar de suficiente flexibilidad a quienes lo utilizan, generando incentivos para seguirlo considerando importante.

Si bien parece responder a casos particulares, el diálogo, visto desde una perspectiva más global, permite dar sentido de coherencia y universalidad a las decisiones de los tribunales regionales y afianzar su legitimidad. Como Zehra Kabasakal argumenta, el hecho de que individuos de distintas culturas participen en actos deliberativos con la meta de generar consensos, es necesario en la construcción de una cultura global de derechos humanos (2006, p. 424).

Por tanto, en la medida en que se aumente e intensifique este diálogo se podrá ir ampliando la coherencia y legitimidad entre los sistemas regionales. No está de más decir que el diálogo contribuye directamente a una mejor comprensión e implementación de los derechos humanos, que es sin lugar a dudas uno de los principales retos en el derecho internacional de los derechos humanos.

\section{Referencias bibliográficas:}

Cano, G. (2015). Diálogo entre jurisdicciones supranacionales de derechos humanos: El Tribunal Europeo de Derechos Humanos y la Corte Interamericana de Derechos Humanos. En M. Revenga y P. Cuenca (eds). El tiempo de los Derechos. Los Derechos Humanos en el Siglo XXI. Madrid: Editorial Dykinson. <https://doi.org/10.7203/cefd.34.9410>.

Carozza, P. y González, P. (2017). The final word? Constitutional dialogue and the Inter-American Court of Human Rights: A reply to Jorge Contesse. International Journal of Constitutional Law, 15 (2), 436-442. <https://doi.org/10.1093/icon/mox021>. 
Carrillo, J. (2009). The European Convention on Human Rights. En F. Gómez, y K. De Feyter, (eds.). International Human Rights Law in a Global Context, (pp. 663-664). Bilbao: Deusto University Press.

Dauvergne, C. (2007). Security and Migration Law in the Less Brave New World. Social \& Legal Studies. Canada: University of British Columbia. <https://doi.org/10.1177/0964663907082734>.

García, J., Nogueira, H. y Bustos, R. (2012). La comunicación entre ambos sistemas y las características del diálogo. En J. García, P. Fernández, P. Asantolaya y R. Canosa (eds.). El diálogo entre los sistemas europeo y americano de derechos humanos (pp. 79-83). Madrid: Civitas-Thompson Reuters.

García, J. (2013). El diálogo entre el Tribunal de Derechos Humanos, los Tribunales Constitucionales y otros órganos jurisdiccionales en el espacio convencional europeo. En F. Mac-Gregor y A. Herrera (eds.). Diálogo jurisprudencial en derechos humanos: entre Tribunales Constitucionales y Cortes internacionales: in memoriam Jorge Carpizo (pp. 219-241). Valencia: Instituto Iberoamericano de Derecho Constitucional.

Garlicki, L. (2012). Conferencia Introductoria: Universalism v. Regionalism? The role of the supranational judicial dialogue. En J. García y A. Coral (Eds). El Diálogo entre los Sistemas Europeo y Americano de Derechos Humanos (pp. 27-64). Madrid: Civitas.

González, P. (2014). La implementación de la Convención Americana de Derechos Humanos en los Sistemas Jurídicos Nacionales: La Doctrina del Control de Convencionalidad. Santiago de Chile: Centro de Estudios de Justicia de las Américas (CEJA).

Gross Espiell, H. (2000). Los Derechos Humanos no enunciados o no enumerados en el Constitucionalismo Americano y en el Artículo 29 C de la Convención Americana sobre Derechos Humanos. Anuario Iberoamericano de Justicia Constitucional, 4, 145-172.

Heyns, C., Padilla, D. y Zwaak L. (2009). A Schematic Comparison of Regional Human Systems. En F. Gómez, y K. De Feyter, (eds.). International Human Rights Law in a Global Context (pp. 163-171). Bilbao: University of Deusto. <http://dx.doi.org/10.1590/S180664452006000100010>.

Kabasakal, Z. (2006). Forging A Global Culture of Human Rights: Origins and Prospects of the International Bill of Rights. Maryland: The Johns Hopkins University Press. <https://doi. org/10.1353/hrq.2006.0014>.

Koskemieni, M. (2005). Global Pluralism: Multiple Regimes and Multiple Modes of Thought. Massachusetts: Harvard University Press.

Neuman, G. (2008). Import, Export, and Regional Consent in the Inter-American Court of Human Rights. The European Journal of International Law (pp. 101-123). <https://doi. org/10.1093/ejil/chn002>.

Pauwelyn, J. (2003). Conflict of norms in public international law: how WTO law relates to other rules of international law. Cambridge: Cambridge University Press. <https://doi.org/10.1017/ CBO9780511494550>.

Piovesan, F. (2014). Derechos Humanos e impacto del Sistema Interamericano. En A. Von Bogdandy, H. Fix-Fierro y M. Morales (eds.). Ius Constitutionale Commune en América Latina: Rasgos, potencialidades y desafíos (pp. 61-84). México: Universidad Nacional Autónoma de México, Max Plack Institut für ausländisches öffentliches Recht und Völkerrecht e Instituto Iberoamericano de Derecho Constitucional. <https://doi.org/10.12957/ dep.2017.28029>.

Slaughter, A. M. (1994). A Typology of Transjudicial Communication. Richmond: University of Richmond Law Review. 
Steiner, C y Uribe, P. (2014). Convención Americana sobre Derechos Humanos comentada. México: Suprema Corte de Justicia de la Nación de México, Fundación Konrad Adenauer y Konrad-Adenauer-Stiftung e. V.

Trachtman, J. (2013). The Future of International Law: Global Government. Cambridge: Cambridge University Press. <https://doi.org/10.1017/cbo9781139565585>.

Von Bogdandy, A. (2014). Ius Constitutionale Commune Lationamericanum. Una Aclaración Conceptual. En A. Von Bogdandy, H. Fix-Fierro y M. Morales (eds.). Ius Constitutionale Commune en América Latina: Rasgos, potencialidades y desafíos. México: Universidad Nacional Autónoma de México, Max Plack Institut für ausländisches öffentliches Recht und Völkerrecht e Instituto Iberoamericano de Derecho Constitucional. <https://doi. org/10.12957/dep.2017.28029>.

\section{Convenciones, tratados y conferencias}

ONU (1945). Carta de la ONU. Firmada el 26 de junio de 1945 en San Francisco.

- (1948). Declaración Universal de los Derechos Humanos (DUDH). Adoptada el 10 de diciembre de 1948 en París.

Comisión de la Unión Africana (1995). Protocolo a la Carta Africana de Derechos Humanos y de los Pueblos (Protocolo de Maputo), adoptada el 11 de julio del 2003 en Maputo.

Comité creado por la Organización para la Unidad Africana [en la actualidad reemplazada por la Unión Africana] (1981). Carta Africana de Derechos Humanos y de los Pueblos, adoptada el 27 de julio de 1981 en Banjul.

Consejo de Europa (1950). Convenio Europeo para la Protección de los Derechos Humanos y de las Libertades Fundamentales (Convención Europea de Derechos Humanos), adoptada el 4 de noviembre de 1950.

ONU (1966). Pacto Internacional de Derechos Civiles y Políticos (ICCPR, por su sigla en inglés). Adoptado el 16 de diciembre de 1966 en Nueva York.

- (1969). Convención de Viena sobre el Derecho de los Tratados (Convención de Viena). adoptada el 23 de mayo de 1969 en Viena.

OEA (1969). Convención Americana sobre Derechos Humanos (Pacto de San José de Costa Rica), suscrita, el 22 de noviembre de 1969 en San José

OMC (1994). Acuerdo de Marrakech por el que se establece la Organización Mundial del Comercio, adoptado en Marrakech el 15 de abril de 1994.

\section{Legislación}

Ministerio de Salud de Costa Rica (1995). Decreto Ejecutivo. No. 24029-S. Emitido el 3 de febrero de 1995, publicado en La Gaceta No.45 del 3 de marzo de 1995.

\section{Sentencias}

Corte Africana de Derechos Humanos y de los Pueblos (2013). Caso Rev Christopher Mitikila v. Tanzania, Aplicaciones 009/2011 y 011/2011. Sentencia de 14 de junio de 2013.

Corte IDH (2001). Caso Baena Ricardo y otros Vs. Panamá. Fondo, Reparaciones y Costas. Sentencia de 2 de febrero de 2001. Serie C No. 72.

- (2006). Caso de las Masacres de Ituango Vs. Colombia. Sentencia de 1 de julio de 2006. 
- (2009). Caso González y otras ("Campo Algodonero") Vs. México. Excepción Preliminar, Fondo, Reparaciones y Costas. Sentencia de 16 de noviembre de 2009. Serie C No. 205, párr. 43.

- (2011). Caso Fontevecchia y D'amico Vs. Argentina. Fondo, Reparaciones y Costas. Sentencia de 29 de noviembre de 2011. Serie C No. 238.

- (2012). Caso Atala Riffo y Niñas Vs. Chile. Fondo, Reparaciones y Costas. Sentencia de 24 de febrero de 2012. Serie C No. 239

- (2012). Caso Artavia Murillo y otros (Fecundación in vitro) Vs. Costa Rica, Excepciones Preliminares, Fondo, Reparaciones y Costas. Sentencia de 28 noviembre de 2012. Serie C No. 257

- (2016). Caso Trabajadores de la Hacienda Brasil Verde Vs. Brasil. Excepciones Preliminares, Fondo, Reparaciones y Costas. Sentencia de 20 de octubre de 2016. Serie C No. 318.

Corte Suprema de Costa Rica (2000). Inconstitucionalidad del Decreto Ejecutivo No. 24029-S de 3 de febrero de 1995. Sentencia de 15 de marzo de 2000. No. 2000-02306. Expediente No. 95-001734-007-CO.

Grand Chamber (2005). Caso Hirst Vs. Reino Unido No. 2 (Application no. 74025/01). Sentencia de 6 de octubre de 2005.

TEDH (1976). Caso Handyside Vs. Reino Unido. Sentencia de 7 de diciembre de 1976.

- (1978). Caso Tyrer Vs. Reino Unido. Sentencia de 25 de abril de 1978. Serie A No. 72.

- (1989). Caso Soering Vs Reino Unido. Sentencia de 7 de julio de 1989. Serie A, No. 161.

- (2004) Caso Vo. Vs. Francia (No. 53924/00), GC. Sentencia de 8 de julio de 2004.

- (2005). Caso Siliadin Vs. Francia (No. 73316/01). Sentencia de 26 de julio de 2005.

- (2007). Caso Evans Vs. Reino Unido (No. 6339/05). Sentencia de 10 de abril de 2007.

- (2010). Caso Rantsev Vs. Chipre y Rusia (No. 25965/04). Sentencia de 7 de enero de 2010.

Tribunal Penal Internacional para la Ex Yugoslavia (2001). Caso Fiscal Vs. Dragoljub Kunarac, Radomir Kovač y Zoran Vuković (No. IT-96-23-T \& IT-96-23/1-T). Sentencia de 22 de febrero de 2001.

\section{Observaciones, opiniones, recomendaciones e informes}

Caldas, R. F. (2016). Acto inaugural del Año Judicial Interamericano 2016. Celebración del 113 Periodo Ordinario de Sesiones. San José, Costa Rica. 15 de febrero a 2 de marzo de 2016. http://www.corteidh.or.cr/docs/comunicados/cp_04_16.pdf

Comisión Africana de Derechos Humanos y de los Pueblos (2000). Caso Malawi African Association y Otros Vs. Mauritania, Comunicaciones Nos. 54/91, 61/91, 98/93, 164/97196/97 y 210/98. Decisión de 11 de mayo de 2000.

Corte IDH (1999). Opinión Consultiva OC-16/99 de 1 de octubre de 1999. Serie A No. 16

- (2014). Opinión Consultiva OC-21/14 de 19 de agosto de 2014. Serie A No. 21. - (2016a). Opinión Consultiva OC-22/16 de 26 de febrero de 2016. Serie A No. 22.

- (2016b). Informe anual 2016, p. 194.

Corte IDH y TEDH. (2015). Diálogo transatlántico: selección de jurisprudencia del Tribunal Europeo y la Corte Interamericana de Derechos Humanos / Corte Europeo de Derechos Humanos. Países Bajos: Wolf LP.

ONU (2006). Comisión de Derecho Internacional. Fragmentation of International Law: Diffculties Arising from the Diversification and expansion of International Law: Report of the Study Group of the International Law Commission. UNGA A/CN.4/L.682. Agosto de 2006. 